\title{
Vitamin C as Contributor to the Total Antioxidant Capacity - Importance, Occurrence, Methods of Determination
}

\section{Aurelia Magdalena Pisoschi*}

University of Agronomic Sciences and Veterinary Medicine of Bucharest, Faculty of Veterinary Medicine, Bucharest, Romania

Vitamin $\mathrm{C}$ is a water-soluble antioxidant vitamin which can be found in many biological systems and foodstuffs (fresh vegetables and fruits). It is important in synthesizing collagen, in the absorption of iron, and is also involved in wound healing and osteogenesis. It is represents the $\mathrm{L}$-enantiomer of ascorbic acid and is recognized as one of the most common electroactive biocompound. Significant sources include blackcurrant, citrus fruit, leafy vegetables, tomatoes, green and red peppers [1-4]. Humans, some other primates, and guinea pigs lacking L-gulonolactone oxidase due to a genetic mutation, are unable to synthesize ascorbic acid and diet is the unique source [5].

Ascorbic acid is easily degraded by enzymes and atmospheric oxygen. Its oxidation can be accelerated by heat, light, and heavy metal cations, especially in alkaline media [6]. Its content variation determined by this lability implies the use of peformant methods of analysis in complex media during the stages of manufacturing and storage, as vitamin $\mathrm{C}$ represents a quality indicator and contributor to the antioxidant properties of foodstuffs $[7,8]$.

Ascorbic acid behaves as a free-radical scavenger, can quench singlet oxygen, or act as chelating agent [6]. Excessive ascorbic acid amounts may result in taste or aroma alteration, caused by the inhibition of natural processes occurring in food [8]; an ascorbic acid excess can lead to gastric irritation, and its metabolic product (oxalic acid) can cause renal problems [8]. Another drawback of its excess is the ability to act as a prooxidant in the presence of heavy metal cations [9]. Traditional methods for ascorbic acid assessment involve titration with an oxidant solution: Dichlorophenol Indophenol (DCPIP) [6], potassium iodate [10] or bromate [11].

Fluorimetric methods based on dehydroascorbic acid reaction with o-phenylene diamine were also used for ascorbic acid estimation [12]. UV-VIS absorbance was applied to ascorbic acid quantification in horticultural products [13]. Other optical methods for vitamin $\mathrm{C}$ estimation involve spectrophotometrical determination of iodine reacted with ascorbic acid [14], spectrophotometrical determination after the analyte reaction with hexacyanoferrate III [15], with complexes such as $\mathrm{Fe}(\mathrm{III})-1,10$ phenantroline [16] or $\mathrm{Cu}(\mathrm{II})$-neocuproine [17] or with dinitrophenylhydrazine [18], and chemiluminescence [19]. Ascorbic acid is able to quench DPPH., yielding the absorbance diminution of the free radical solution at $515 \mathrm{~nm}$, with linearity obtained up to $50 \mu \mathrm{M}$, which consititutes a premise for the future use of vitamin $\mathrm{C}$ as a reference for total antioxidant capacity assessment [20]. Vitamin C has been successfully determined by HPLC with electrochemical detection $[21,22]$.

Electrochemical methods allow rapid, simple, selective and sensitive determination of low molecular weight antioxidants, including ascorbic acid and drugs, without the necessity of laborious sample pretreatment or time consuming separation. Voltammetry is based on imposing a controlled potential variation in time, with the recording of the intensity-potential dependence-the voltammogram [8]. In cyclic voltammetry, the potential varies as a triangular wave form and the analytical signal is represented by the intensity of the anodic peak, corresponding to ascorbic acid oxidation to dehydroascorbic acid. In differential pulse voltammetry regular voltage pulses are superimposed on potential linear sweep or stair steps. The current is measured immediately before each potential change, and the current difference is plotted as a function of potential. In differential pulse techniques, a differential value is actually measured, aiming to minimize the interference of the capacitive current and to enhance the contribution of the faradaic one [23].

A cyclic voltammetric method at bare Pt disc working electrode allows viable vitamin $\mathrm{C}$ determination in fruit juices, with linearity obtained between 0.1 and $10 \mathrm{mM}$. The richest sample in ascorbic acid concentration was lemon juice, showing a $1.93 \mathrm{mM}$ ascorbic acd content. The degrees of recovery were comprised between $94.35 \%$ and $104 \%$. Comparative voltammetric assessment of vitamin $C$ at unmodified carbon paste and Pt strip working electrodes proved better sensitivity of carbon paste electrode: the limit of detection and the limit of quantification obtained by differential pulse voltammetry were 0.087 $\mathrm{mM}$ and $0.29 \mathrm{mM}$ respectively, when a Pt electrode was used, vs. the values of $0.02 \mathrm{mM}$ and $0.068 \mathrm{mM}$ obtained with carbon paste [24].

In media where interference occurence is expected, the use of modifiers enhances the catalytic peak current of the analyte of interest and reduces overvoltage, allowing better peak separation from interferent compounds. The electrooxidation and determination of ascorbic acid were studied, at unmodified carbon paste and tetrabromo-p-benzoquinone modified carbon paste electrodes, $\mathrm{pH} 7.0$, in phosphate buffer. Thus, a decrease in the overvoltage of approximately $430 \mathrm{mV}$ and an enhancement of the peak current is achieved with the modified electrode [25]. A carbon paste electrode modified with a 2,2'-(1,8-octanediylbisnitriloethylidine)-bishydroquinone exhibited high electrocatalytic activity $v s$ ascorbic acid; the current was enhanced, in comparison to the unmodified electrode. Differential pulse voltammetric calibration curves for ascorbic acid were obtained over the range of 5-30 $\mu \mathrm{M}$ and $40-1,500 \mu \mathrm{M}$, respectively allowing viable assessment in pharmaceutials [26].

Potentiometric biosensors based on ionic species concentration change following a biocatalytical reaction or, more often amperometric biosensors relying on electron transfer reactions, were also applied

*Corresponding author: Aurelia Magdalena Pisoschi, University of Agronomic Sciences and Veterinary Medicine of Bucharest, Faculty of Veterinary Medicine, Bucharest, Romania, E-mail: aureliamagdalenapisoschi@yahoo.ro

Received December 03, 2013; Accepted December 04, 2013; Published December 06, 2013

Citation: Pisoschi AM (2013) Vitamin C as Contributor to the Total Antioxidant Capacity - Importance, Occurrence, Methods of Determination. Biochem Anal Biochem 2: e146. doi: 10.4172/2161-1009.1000e146

Copyright: $\odot 2013$ Pisoschi AM. This is an open-access article distributed under the terms of the Creative Commons Attribution License, which permits unrestricted use, distribution, and reproduction in any medium, provided the original author and source are credited. 
Citation: Pisoschi AM (2013) Vitamin C as Contributor to the Total Antioxidant Capacity - Importance, Occurrence, Methods of Determination Biochem Anal Biochem 2: e146. doi: 10.4172/2161-1009.1000e146

in specific ascorbic acid quantification in real time. The reduction of $\mathrm{Cu}^{2+}$ in the ascorbate oxidase structure to $\mathrm{Cu}^{+}$by ascorbate, determines changes in the electronic density on the surface of a potentiometric transducer based on a poly(ethylene-co-vinyl acetate) matrix, fixed on a graphite-epoxy composite [27]. Amperometric ascorbic acid biosensors were obtained by ascorbate oxidase immobilization on a nylon net or on a collagen membrane, using a Clark oxygen electrode as transducer $[28,29]$.

More recently, Carbon Nanotubes (CNTs) have been used in biosensor development due to their enhanced electroactivity and large surface area, as well as to their good biocompatibility [30,31]. Ascorbate oxidase was covalently immobilized on carboxylated multiwalled carbon nanotubes - polyaniline layer, electrochemically deposited on an $\mathrm{Au}$ electrode [31]. The amperometric response was given by the reduction of molecular oxygen non-consumed in the enzyme reaction, and vitamin $\mathrm{C}$ was assessed in sera, fruit juices and tablets, with results consistent with those provided by the dichlorophenolindophenol method. The different instrumental or titrimetric methods applied to vitamin $\mathrm{C}$ quantitation should be tuned to the nature of the sample analysed.

\section{References}

1. Cathcart RF (1991) A unique function for ascorbate. Med Hypotheses 35: 32 37.

2. Erdurak-Kiliç CS, Uslu B, Dogan B, Ozgen U, Ozkan SA, et al. (2006) Anodic voltammetric behavior of ascorbic acid and its selective determination in pharmaceutical dosage forms and some Rosa species of Turkey. J Anal Chem 61: 1113-1120.

3. Mohora M (2006) Medical Biochemistry. Niculescu Edition, Bucharest Romania.

4. Fatibello-Filho O, da C. Vieira I (2000) L-Ascorbic Acid Determination in Pharmaceutical Formulations Using a Biosensor Based on Carbon Paste Modified with Crude Extract of Zucchini (Cucurbita pepo) J Brazil Chem Soc 11: $412-418$

5. Valpuesta V, Botella MA (2004) Biosynthesis of L-ascorbic acid in plants: new pathways for an old antioxidant. Trends Plant Sci 9: 573-577.

6. Pisoschi AM (2012) Food additives and ingredients-structures, properties, uses. Elisavaros Edition, Bucharest.

7. Popa CV, Danet AF, Jipa S, Zaharescu T (2010) Determination of total antioxidant activity of wines using a flow injection method with chemiluminescence detection. Rev Chim (Bucharest) 61: 11-16

8. Wawrzyniak J, Ryniecki A, Zembrzuski W (2005) Application of voltammetry to determine vitamin $C$ in apple juices. Acta Sci Pol Technol Aliment 4: 5-16.

9. Du J, Cullen JJ, Buettner GR (2012) Ascorbic acid: chemistry, biology and the treatment of cancer. Biochim Biophys Acta 1826: 443-457.

10. Balan D, Pele M, Artimon M, Luta G (2005) Bioactive compounds in sea buckthorn fruits and in some products obtained by their processing. Rev Cyto Biol Veg Bot 28: 364-368.

11. Matei N, Magearu V, Birghila S, Dobrinas S (2004) The determination of vitamin C from sweet cherries and cherries. Rev Chim (Bucharest) 55: 294-296.

12. Arya SP, Mahajan M, Jain P (2000) Non-spectrophotometric methods for the determination of vitamin C. Anal Chim Acta 417: 1-14.

13. Vermeir S, Hertog ML, Schenk A, Beullens K, Nicolaï BM, et al. (2008)
Evaluation and optimization of high-throughput enzymatic assays for fast l-ascorbic acid quantification in fruit and vegetables. Anal Chim Acta 618: 94101.

14. Danet AF, David V, Oancea M (1994) Flow injection analysis system with hydrodynamic injection. Vitamin C determination. Rev Chim (Bucharest) 45 1000-1005.

15. Lenarczuk T, GÅ,ab S, Koncki R (2001) Application of Prussian blue-based optical sensor in pharmaceutical analysis. J Pharm Biomed Anal 26: 163-169.

16. Anwar J, Farooqi MI, Nagra SA, Khan AM (1990) A new method for the spectrophotometric determination of ascorbic acid. J Chem Soc Pak 12: 75-79.

17. Güçlü K, Sözgen K, Tütem E, Ozyürek M, Apak R (2005) Spectrophotometric determination of ascorbic acid using copper(II)-neocuproine reagent in beverages and pharmaceuticals. Talanta 65: 1226-1232.

18. Matsumoto K, Yamada K, Osajima Y (1981) Ascorbate electrode for determination of L-ascorbic acid in food. Anal Chem 53: 1974-1979.

19. Dãnet AF, Badea M, Aboul-Enein HY (2000) Flow injection system with chemiluminometric detection for enzymatic determination of ascorbic acid. Luminescence 15: 305-309.

20. Pisoschi AM (2012) Ascorbic acid capacity of quenching DPPH. spectrophotometrical approach; a premise for the future use of vitamin C as a reference antioxidant in the evaluation of the total antioxidant capacity. Symposium of the Faculty of Veterinary Medicine of Bucharest, Contribution of the Scientific Research to Veterinary Medicine Progress". Bucharest, November 22-23.

21. Iwase $H$ (2000) Use of an amino acid in the mobile phase for the determination of ascorbic acid in food by high-performance liquid chromatography with electrochemical detection. J Chromatogr A 881: 317-333.

22. Rizzolo A. Brambilla A, Valsecchi S, Eccher-Zerbini $P$ (2002) Evaluation of sampling and extraction procedures for the analysis of ascorbic acid from pear fruit tissue. Food Chem 77: 257-262.

23. Danet AF (1996) Electrochemical methods of analysis. Scientifical Edition, Bucharest.

24. Pisoschi AM, Pop A, Negulescu GP, Pisoschi A (2011) Determination of ascorbic acid content of some fruit juices and wine by voltammetry performed at pt and carbon paste electrodes. Molecules 16: 1349-1365.

25. Zare HR, Nasirizadeh N, Mazloum-Ardakani M (2005) Electrochemical properties of a tetrabromo-p-benzoquinone modified carbon paste electrode. Application to the simultaneous determination of ascorbic acid, dopamine and uric acid. J Electroanal Chem 577: 25-33.

26. Mazloum-Ardakani M, Habibollahi F, Zare HR, Naeimi $H$ Nejati M (2009) Electrocatalytic oxidation of ascorbic acid at a 2,2'-(1,8-octanediylbisnitriloethylidine)-bis-hydroquinone modified carbon paste electrode. J Appl Electrochem 39: 1117-1124.

27. Fernandes JCB, Kubota LT, de Oliveira Neto G (1999) Potentiometric biosensor for I-ascorbic acid based on ascorbate oxidase of natural source immobilized on ethylene-vinylacetate membrane. Anal Chim Acta 385: 3-12.

28. Tomita IN, Manzoli F, Fertonani FL, Yamanaka H (2005) Amperometric biosensor for ascorbic acid. Eclét Quim 30: 37-43.

29. Pisoschi AM, Negulescu GP, Pisoschi A (2010) Ascorbic acid determination by an amperometric ascorbate oxidase-based biosensor. Rev. Chim. (Bucharest) 61: $339-344$

30. Dechakiatkrai C, Chen J, Lynam C, Shin KM, Kim SJ (2008) Direct ascorbic acid detection with ferritin immobilized on single-walled carbon nanotubes. Electrochem Solid St 11: K4-K6.

31. Chauhan N, Narang J, Pundir CS (2011) Fabrication of multiwalled carbon nanotubes/polyaniline modified Au electrode for ascorbic acid determination. Analyst 136: 1938-1945.
Citation: Pisoschi AM (2013) Vitamin C as Contributor to the Total Antioxidant Capacity - Importance, Occurrence, Methods of Determination. Biochem Anal Biochem 2: e146. doi: 10.4172/2161-1009.1000e146 